\title{
Postoperative outcome of a giant incisional hernia resolved by anterior component separation technique
}

Lecturer Bogdan SOCEA ${ }^{1,2}, \mathrm{MD}, \mathrm{PhD}$, Lecturer Camelia DIACONU ${ }^{3,4}, \mathrm{MD}, \mathrm{PhD}$, Conf. Dr. Ovidiu Gabriel BRATU5,6, MD, PhD, Univ. Assist. Tiberiu Paul NEAGU7,8, MD; PhD, Univ. Assist. Cristinel Dumitru BADIU ${ }^{2,9}, \mathrm{MD}, \mathrm{PhD}$, Grigore BUSOI ${ }^{10}, \mathrm{MD}$, Prof. Dr. Vlad Denis CONSTANTIN ${ }^{1,2}, \mathrm{MD}, \mathrm{PhD}$

${ }^{1}$ Department of General Surgery, Emergency Clinical Hospital "Sf. Pantelimon", Bucharest ${ }^{2}$ Clinical Department No. 10, "Carol Davila" University of Medicine and Pharmacy, Bucharest ${ }^{3}$ Department of Internal Medicine, Clinical Emergency Hospital of Bucharest

${ }^{4}$ Clinical Department No. 5, "Carol Davila" University of Medicine and Pharmacy, Bucharest ${ }^{5}$ Department of Urology, "Dr. Carol Davila" Central Military Emergency University Hospital, Bucharest ${ }^{6}$ Clinical Department No. 3, "Carol Davila" University of Medicine and Pharmacy, Bucharest ${ }^{7}$ Department of Plastic Surgery and Reconstructive Microsurgery, Emergency Clinical Hospital of Bucharest ${ }^{8}$ Clinical Department No. 11, "Carol Davila" University of Medicine and Pharmacy, Bucharest ${ }^{9}$ Department of General Surgery, Emergency Clinical Hospital "Bagdasar Arseni", Bucharest ${ }^{10}$ Family Medicine Office, Bucharest

ABSTRACT
We present the case of a 64 years old man, who was admitted in our surgical clinic with a giant median
incisional hernia after a previously colonic resection and anastomosis for a colonic tumor. We had to deal
with a loss of domain giant ventral hernia.
The patient was known with chronic obstructive pulmonary disease (COPD) and chronic coughing, that
was an aggravating condition.
We did an alloplasty in Rives-Stoppa manner, accompanied by an anterior component separation.
The clinical postoperative outcome was very good and we present the results."

Keywords: loss of domain, giant hernia, component separation

\section{INTRODUCTION}

Component separation was first described and used by Ramirez in 1990 as a result of a study on human corpses (1).

Component separation is a relativelly new technique used in cases that need adequate coverage for big abdominal wall defects such as a loss of domain ventral hernia. Anterior component separation requires surgical dissection of subcutaneous plain, from medial to lateral. Then, a longitudinal fasciotomy immediatelly lateral (at $1.5-2 \mathrm{~cm}$ ) to the lateral margin of rectus abdominis muscle, and dissection on the plane between external and internal oblique muscles allows an extension to medial of rectus

\section{Corresponding author:}

Bogdan Socea, Emergency Clinical Hospital “Sfântul Pantelimon”, Șoseaua Pantelimon no. 340-342, Sector 2, Bucharest 021659, 1st floor, 
abdominal sheets. This release allows for medial advancement of the fascia and closure of up to $20 \mathrm{~cm}$ wide defects in the midline area (2). The surgeon has to take care not to excessively damage the vascularization, nor the innervation of the muscles.

The extensive subcutaneous lateral dissection had been associated with ischemia of the midline skin edges.

\section{CASE PRESENTATION}

A 64-years old man presented to our emergency room with abdominal pain and a giant, irreducible ventral median incisional hernia.

The patient presented a median xifo-pubian scar (left hemicolectomy) and also a long right subcostal scar (Kocher incision for a difficult cholecistectomy).

Common blood tests and abdominal $\mathrm{X}$ ray showed no modification.

A slightly difficulty of breathing determined us to run a spirometry, that proved obvious air flow obstruction (FEV $63 \%, \mathrm{FEV}_{1} / \mathrm{FVC} 57 \%$ ).

Abdominal CT scan confirmed the diagnosis of ventral hernia with a maximum defect on midline of $15 \mathrm{~cm}$. There were no signs of secondary tumors. CT scan also showed multiple adherences between small and large bowel and anterior abdominal wall on the midline and also in right upper quadrant (at the cholecistectomy scar, with no parietal defect at that level). This was the clinical tactical reason to avoid, in this case, as long as it would have been technically possible, posterior component separation.

The type of mesh that we chose was a polypropylene one. Its' characteristics are fit for a retromuscular montage in Rives-Stoppa manner, as they almost simultaneously described independently this procedure $(3,4)$. In our experience, polypropylene mesh remains the best option for intra- or retromuscular montage (511). It is well tolerated and in this type of montage we do not have to take care about adhesion syndrome between bowels and mesh surface.

We did the operation under general anesthesia. The operating time was 240 minutes. Intraoperative, after anterior component separation we could achieve the medial margins of linea alba coming into contact without tension, so a further posterior separation seemed useless. We fixed two aspirative subcutaneous drains. The postoperatory evolution was good. Drains collected $50-100 \mathrm{ml}$ serous fluid daily, till day 9 , when both drains were suppressed.

The patient was discharged on day 10. On day 14 follow-up, the outcome was excellent as it could be seen in figure 1 . A very small skin necrosis was observed but it was managed conservatory, and a small secondary suture 10 days after. As described in literature, the midline skin

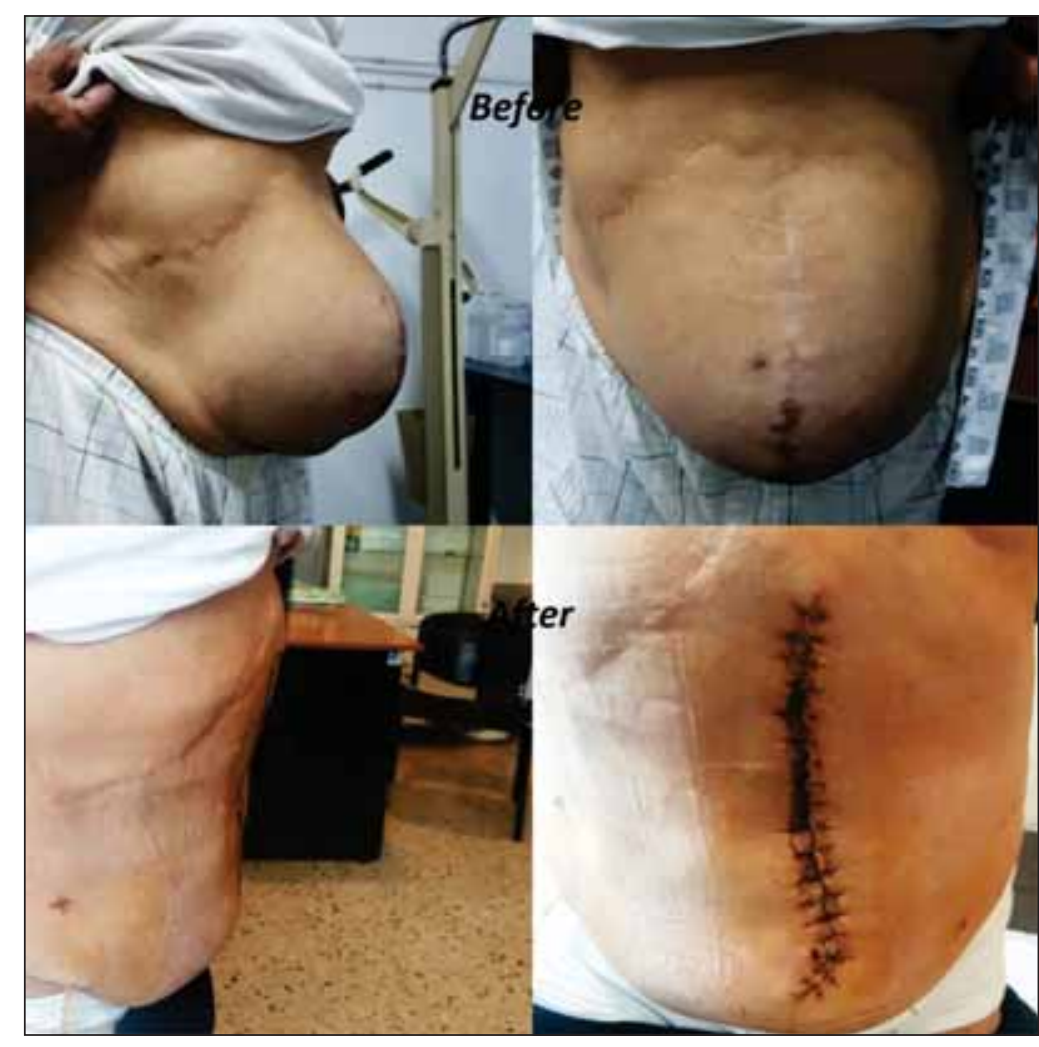

FIGURE 1. Clinical postoperative outcome compared to initial situation (2 weeks after surgical procedure) 
necrosis could be a consequence of extensive lateral subcutaneous dissection. In our case it was a minor complication due to its small surface.

\section{CONCLUSIONS}

In several difficult cases anterior component separation can achieve alone sufficient medial translation for a good abdominal wall repair without parietal tension.

The particularity of this case was association between loss of domain giant ventral hernia and COPD. In spite of this difficult association, the result was very good.

\section{REFERENCES}

1. Ramirez OM, Ruas E, Dellon AL. "Components separation" method for closure of abdominal-wall defects: An anatomic and clinical study. Plast Reconstr Surg. 1990;86(3):519-26.

2. Heller L, McNichols $\mathrm{CH}$, Ramirez OM. Component separations. Semin Plast Surg. 2012;26(1):25-8.

3. Rives J, Lardennois B, Pire JC, Hibon J. Large incisional hernias. The importance of flail abdomen and of subsequent respiratory disorders. Chirurgie. 1973;99(8):547-63.

4. Stoppa R, Petit J, Abourachid H, Henry X, Duclaye C, Monchaux G, Hillebrant JP. Original procedure of groin hernia repair: Interposition without fixation of Dacron tulle prosthesis by subperitoneal median approach. Chirurgie. 1973;99(2):119-23.

5. Carap A, Popa F, Socea B, Bobic S, Ciudin A, Constantin VD. Materials used for temporary abdominal closure following decompression laparotomy in the abdominal compartment syndrome. Industria Textilă, 2015;66(3): 136-141.

6. Constantin VD, Carâp A, Socea B, Ficai A, Albu MG, Păunică-Panea G. The influence of synthetic material meshes on the surgical repair of abdominal wall defects. Romanian Journal of Materials. 2015;45(3): 290-297.

7. Socea B, Socea LI, Bratu OG, Mastalier B, Dimitriu M, Carâp A, Constantin VD. Recurrence rates and mesh shrinkage after polypropylene vs. polyester mesh hernia repair in complicated hernias. Revista de Materiale Plastice, 2018; 55(1): 79-81.

8. Vlad Dumitru Baleanu, Denis Vlad Constantin, Anca Pascal, Dragos Ovidiu Alexandru, Simona Bobic, Bogdan Socea, Ana Laura Manda, Dragos Davitoiu, Anda Lorena Dijmarescu, Ion Georgescu, Cecil Sorin Mirea. Use of synthetic protetic materials in surgical abdominal defects analysis of the advantages and lack of the Liechtenstein method. Rev. Chim., 2018; 69(7): 1740-3.
9. Tiberiu Stefanita Tenea Cojan, Lucretiu Radu, Dragos Davitoiu, Ionela Mihaela Vladu, Vlad Dumitru Baleanu, Diana Clenciu, Cristina Gabriela Ene, Bogdan Socea. The importance of the chemical composition of synthetic nets used in repair of parietal deffects. Rev. Chim., 2018;69(10): 2677-81.

10. Bogdan Socea, Alexandru Carâp, Ovidiu Gabriel Bratu, Camelia Cristina Diaconu, Mihai Dimitriu, Laura lleana Socea, Simona Bobic, Vlad Denis Constantin. The role of the composite and biologic meshes in the trocar site hernia repair following laparoscopic surgery. Revista de Materiale Plastice, 2018; 55(2): 146-8.

11. Trandafir A, Vasile D, Davitoiu D, Manda AL, Socea B, Georgescu I, Baleanu V. The new self-gripping mesh and it's benefits in inguinal hernia repair - review of the literature. Research and Science Today, 2018;1(15): 132-9. 